\title{
The Introduction of Genre Approach to the Development of the Student Competence in Translating Scientific Texts on Linguistics
}

\author{
L. O. Maksymenko \\ Kyiv National Linguistic University, Kyiv, Ukraine \\ Corresponding author. E-mail: 1.o.maksymenko@gmail.com
}

Paper received 24.10.18; Accepted for publication 29.10.18.

\begin{abstract}
https://doi.org/10.31174/SEND-PP2018-181VI75-14
\end{abstract}
\begin{abstract}
The ability to perform a preliminary text analysis with the aim of determining its functional style and speech genre is an essential component of translation competence. In this respect, the teaching approaches focused on the genre variability of discourse were analyzed. The results allow us to lay the ground for a valid hypothesis about the potential of their implementation in training translation. This paper offers some tasks for developing the methodology of training students of philological departments to translate scientific texts on linguistics.
\end{abstract}

Keywords: genre approach, genre analysis, translation training, teaching translation of scientific texts.

Introduction. The goal of this study grew out of the need for training specialists in scientific translation caused by an increasing number of projects of a humanitarian nature aimed at the diverse development of world science. The interest in academic communication becomes even more evident due to the expansion of international scientific and professional contacts, the gradual involvement of Ukrainian scholars into international cooperation and the modernization of education in the light of the Bologna process.

Thus, the translation of scientific texts in Humanities and Social Science is becoming more and more relevant. Previous analysis of the specific character of translation activities in the sphere mentioned above demonstrates that the scholars do their research and interpret the facts or observations in Translation Studies on the grounds of a particular genre. The translator must not only understand the source text but also be able to transfer the sense comprehensively in corresponding terms and stylistics adopted in the relevant field. Avoiding these requirements will inevitably lead to discrepancies of the semantic nature and, consequently, to semantic failures. Teaching translation of scientific texts requires the development of the methodology which is consistent with its ultimate goal within Ukrainian educational context aimed at attracting our future and present scientists to international academic life, enabling the possibility to publish their works for a globalized audience and to communicate with scholars from other countries.

Despite a large number of developed methods, systems and complexes of exercises the issue of training future translators is still relevant. And this is not surprising as methodological science like any other constantly develops, interacts with other sciences, relies on their teaching tools, achievements and uses them in its field. The educational process leads to achieving certain results when it launches its fundamental principles on the theoretical evidence of a particular approach. In this paper, we would like to draw attention to one of the approaches, namely the genre approach. We believe this approach is efficient for teaching translation. The main advantage of the genre approach is that considering its concepts, students learn to produce foreign texts based on their linguistic and extralinguistic features. It gives the opportunity to teach the students how to represent object-oriented and subjectoriented content by updating a number of categories in these types of content. One can say that students go into the space of discourse; they analyze, interpret and synthesize information taking into account all the characteristics of the linguistic situation.

Overview of publications on the topic. Teaching approach focused on the genre variability of discourse has recently gained widespread acceptance in the theory and practice of teaching foreign languages in particular for special purposes. The scholarly papers written by Englishspeaking authors discuss such issues as criteria for identifying genres with the aim of describing and learning [1], the correlation between the concepts of 'genre' and 'register' [5], the potential of the genre approach for developing writing skills [3], the efficiency of a procedural approach to teaching professional genres [2], the role of genres in solution of the communicative and social tasks of the representatives of discursive communities [9].

At present, genre concept is one of the main principles of teaching written communication for scientific and academic purposes. This groundwork has formed the basis for the genre approach the characteristic features of which focus on the general structural-compositional, functional-semantic and linguistic peculiarities of the academic genres. The effectiveness of this approach is in its ability to cover a wide range of multi-level genre features, provide a general picture of a particular genre texts organization and stimulate the rapid development of the basic skills of creating relevant texts.

Purpose of the article is to analyze the various methods of the genre approach to academic writing and the development of the implementation of this approach frameworks; summarize the achievements obtained in this field in order to indicate the potential of their application for developing the methodology of training students of philological departments to translate scientific texts on linguistics.

Materials and methods. The data for this study have been obtained using the complex of methods, including analysis, comparison, and generalization of academic literature. Basic information to support my proposal comes from American and Australian research papers. Application of dialectic, objective principles has made it possible to consider some frameworks of the genre approach in training.

Findings and their discussion. As experience shows, the genre approach can be successfully implemented in 
the process of training students of linguistic faculties in the translation of the scientific text, since they are supposed to have an intimate acquaintance with Linguistics and related sciences. The conceptual model, grounded on the genre approach, includes the mastery of scientific genres as static models and creative processes, contributes to the successful formation of genre-discursive competence, which is a necessary component of translation competence.

First of all, it should be noted that genres are the most important means of producing and codifying scientific knowledge: modern science implements through typical communicative formats - articles, monographs, scientific reports, abstracts, annotations, etc. They are ratified and supported by convention activities of various scientific communities. Representatives of these professional groups protect the existing stereotypes of scientific communication that provides the relative stability of genre forms as an important precondition for their common usage, acceptable for everybody.

Each of the scientific genres, as well as general, also reveals individual stylistic features. Thus, in the conference abstracts, the method of presentation of the material, as in other scientific genres, is formally logical but unlike the genre of the article, there is no such thoroughness of the statement that is a mandatory feature of a scientific article. The main functions of the scientific style of speech are to inform and persuade. They exist in the form of concept substantiation, hypothesis, proof of the veracity of the theory, generalized information about the research results, classifications, phenomena explanation, certain knowledge systematic presentation, achievements, conclusions, recommendations, proposals, etc. The scholars define the method of describing the material in the scientific literature as a formal-logical (collaborative). And it (the method) determines the choice of the system of language (lexical, grammatical) means for creating a scientific text as a completed communicative act, organized according to the current norms of this language. The scientific text, demonstrating the use of morphologicalsyntactic and lexical-grammatical constructions in their 'natural' environment for the scientific concepts description, is an example of monologue scientific speech and the basis for launching the actual scientific statement. Consequently, the scientific text serves as a means of teaching the language and as an object of study. In the latter case, the subject matter under consideration is the structural and content organization, communicative guidance, compositional completeness, different types of lexical, grammatical, logical and stylistic links between text elements, information sufficiency and density, different ways of presenting scientific thought, etc.

A well-known British linguist G. Widdowson argues that the discourse of science is a universal means of communication implemented in various languages with the help of texts [10]. These texts as a universal means of scientific communication provide a variety of opportunities - from access to new research methods to the chance to publicize the results of their research in the global scientific community. This leads to the extension of certain standards in this area required by prestigious international journals. Their canons affect the way of scientific communication in other languages, in particular, Ukrainian.

Methodologically, translation training is quite diverse, with a wide range of approaches and methods. Their choice and application depend on many factors: the philosophy of education, the level of student knowledge, the purpose and types of translation, etc. It is possible to combine them into two main approaches: the first one focuses on the product of the translation process - the text, and the second - the procedural one, which is primarily interested in the translation process. On the one hand, students must know all the important components and features of the text, its organization, so that the target text meets all the norms of the target language. On the other hand, translation is a creative process that involves different strategies developing for translation problems solving. It helps to create and elaborate thoughts, requires constant work on the text and attentive attitude to its perception by native speakers of the target language. The subject of evaluation is the final written product as well as the process of its enhancement and improvement, the choice of the optimal variant from several possible. Accordingly, the translation should correlate with such mental activity as thinking and planning of translation, preparing working versions (drafts) and their gradual improvement, that is, a certain algorithm of actions. Students discuss their texts with a teacher and other students. This procedural approach allows them to improve their skills, demonstrate professional qualities, adapt to future professional activities, as the translators often perform their work jointly in projects, where everyone fulfils their part. Such an approach contributes to the motivation for learning, relieves the hesitation in decision-making and fear of mistakes because of a strict teacher's control.

The genre approach, for one thing, involves studying the typical organization of various genres - translation products. However, genre pedagogy takes a special interest (in the spirit of socio-constructivism) to the study of contextual sources of genres. Such a social orientation of this pedagogical approach, as well as the use of the elements of procedural learning (preparation of several drafts of the target text, its analysis and group discussion), enable us to position it as a methodology that fully corresponds to modern pedagogical ideas.

Considering some frameworks of genre approach in training, it is important to point out that the idea of applying the genre concept appeared in two academic schools, such as Australian systemic functional linguistics (based on the works of M. A. K. Halliday, R. Hasan and J. R. Martin (ASFLA)) and genre analysis by J. M. Swales and his followers, developed on the bases of American new rhetoric.

It is possible to assume that in Australia the genre approach was designed to teach English as a native and second language in secondary schools and train adult workers (migrants). For a long time, the attention here was focused on linguistic and discursive features of genres, and later on their contextual peculiarities. The training method offered by linguists included three consecutive stages: 1) presentation of certain text types required by the school curriculum; highlighting the key social function of one or the other text; an explanation of how to organize its information structure and an explication of 
the main lexical-grammatical features; 2) modelling by students a certain text type in an interactive communication with a teacher; 3 ) writing individual texts - samples of a particular genre based on the knowledge and skills acquired during the first and second stages.

The pedagogical model, developed by Australian scholars, focuses on an explicit, to some extent formalistic teaching of some school genres. With regard to the genre analysis of J. M. Swales and his followers, his pedagogical backgrounds were shaped by the significant influence of new rhetoric with its special emphasis on the social, cultural and institutional contexts of different genres. J. M. Swales' works supplemented the genre concept as a socio-communicative and socio-cultural phenomenon by focusing on the formal-structural and semantic genre features of various texts, as well as some linguistic vision of their peculiarities. Such a linguistic approach to training has become widely known in the teaching of English for academic purposes.

At present, the genre approach of both directions has a tendency to study the thematic content and the language of genres inseparably from the sociocultural contexts of their generation and interpretation. Australian methodology and genre analysis of J. M. Swales have many common features and specific methodological techniques that have become the basis of a variety of textbooks and teaching materials on English academic and scientific communication.

The results of the analysis of genre approach methods to academic writing and the development of the application of this approach framework $[4 ; 6 ; 7 ; 8]$ give the opportunity to use its main provisions and develop the methodology of training students of philological departments to translate scientific texts on linguistics. Here are examples of possible tasks for such training.

At the first stage of translation training, students have the opportunity to find out the contextual specifics of the genre chosen as the subject of consideration and study. First, the teacher encourages students to reflect on factors such as the role of the author and the recipient of the genre, its purpose, as well as institutional and sociocultural values and expectations that influence the production and interpretation of the source texts of a particular genre. For example, students are given a text on a familiar topic and some tasks relating to the text contextual characteristics.

Example of a task. Read the text and answer the questions:

What is the purpose of the text? What can you say about its overall style? Who is the author of the text? Whom is the text assigned to? What general knowledge and social values does it reflect? How do all these factors affect the linguistic peculiarities of the text? What rhetorical strategy is used in the first move of the abstract? What strategy is used to present the study described in the abstract as a novel one? What examples of meta-text can you find in the abstract? What is, in your opinion, their role? How would the removal of these phrases influence the text? How does the final move present the outcome of the study?

Students discuss the answers to these questions with each other, and then all together with the teacher.
Example of a task. Briefly describe the context of the text based on the notes made during the preliminary discussion.

During their independent work, students should analyze the genres and the contexts of their functioning. The teacher can help students to become the researchers of texts, teach them to use different methods, such as compiling a corpus with parallel texts of one genre on a certain topic or subject; monitoring the features of genres functioning; selecting and studying a group of texts on certain topics in the source and the target languages. Next, students bring the data obtained together with the findings of text analysis of the specific genre samples and use them as a basis for discussion and further performance of their own translations. To begin with, you can offer to students the ready-made enclosures with texts of one genre on the same topic (devoted to a certain scientific subject).

It is necessary to involve the didactic analysis of the genres functional and semantic structure. For example, the analysis of their general formal organization (title, introduction, main part, conclusions and references) and 'text type', which is defined as certain standard models of discursive organization, which occur in different genres. Such models include 'description', 'narrative', 'explanation', 'classification', 'argument', 'cause-effect', 'problem-solving', etc.

Furthermore, it appears quite efficient when students do the tasks aimed at identifying and successful reproducing such discursive structures (categories). So, the students get several texts of different genres and a list of categories. The teacher suggests they match the appropriate ones with the text of each of the genres. Students can compare the texts of such genres as article and review of a book, and try to find out 'description', 'argument', 'explanation' elements, or a combination of them. They can also make sure that the same genre can contain a number of different categories.

There is one more activity, a so-called 'jigsaw' aimed at the combined study of genre structures. Thus, the teacher can mark the components of the genre structure of the text (introduction, main part, conclusions) and available discursive text elements ('problem-solving', 'causeeffect'), and then cut the sheet with the printed text in accordance with the labeled fragments, then distribute the 'bits' of the text to the students and suggest the assignment.

Example of a task. Assemble together separate structural parts of the text with the respective text types.

Example of a task. Now compile the text.

In compliance with the genre analysis, attention should be paid to the general structure of the texts of various scientific genres. For example, the exercise aimed at genre recognition and assimilation.

Example of a task. Working in pairs, analyze individual text fragments and decide which structural section they represent ('introduction', 'methods', 'findings', etc.).

The interpretation of the semantic organization of the texts of various genres in the form of functional semantic text blocks and rhetorical strategies allows students to observe its specificity, determined by the communicative purpose and various pragmatic factors. Typical tasks at this level include defining the blocks (highlighting them) 
in the text and discussing the peculiarities of their strategies application based on the questions suggested by the teacher.

In addition, the genre approach involves the consideration of purely linguistic features of different genres, which comprises both the linguistic characteristics of the whole text and the ways of expressing of certain semantic moments at the level of vocabulary and grammar. At text level, students consider a visual presentation of the typical text of a particular genre, its thematic development and the paragraph structure. At the sentence level, the subject of linguodidactic analysis and training faces the choice of nouns and verbs, the structure of sentences, the use of nominative compounds, the application of the category of modality, syntactic means of introducing new and repetition of the previous information. The lexico-grammatical aspect represents the moments of spelling and punctuation important for a particular target audience, the ways of creating grammatical forms (for example, past tense or participles), and the word-building role of the affixes.

The genre approach brings to attention the consideration of individual linguistic features relevant to a specific genre. For conference abstract or article, for example, the use of grammatical models of passive voice, as well as non-finite forms, is essential in order to indicate the author's findings. Accordingly, the students define and analyze the structural forms, functions of the non-finite forms and passive voice, working in pairs with a partner, and then offer an appropriate way of translation adequate to the communicative specificity of the genre.

It seems sufficient to draw attention to the clichés which verbalize the leading rhetorical strategies in various scientific texts. Often the subject of linguistic analysis is a metatext, which helps to organize a written statement. So students can be offered some sentences with metatext phrases in which they have to fill the gaps with the prepositions. Or they are suggested matching the metatext phrases with their correspondences in the target language. Although these exercises look quite traditional, they create a proper 'foundation' for assimilating important linguistic features of different genres together with the ways of translation.

At the final stages of the study, students integrate their knowledge and perform translation of the texts of different genres under a teacher's observation or without any assistance. It can be either individual translations or performed by a group of students. The manifestation of the elements of the process-based approach involves the preparation of previous (draft) versions of the target text, discussion and processing. Students are aware of clear criteria for assessing the final products which evaluate their level of knowledge of the context, general structure, linguistic characteristics of a particular genre, and requirements for translation quality.

Conclusions. The genre approach may become one of the methodological directions in teaching translation of scientific texts. Its theoretical framework grows out of the modern concept of the genre as a socio-communicative phenomenon. The essence of the approach employs the concept of the genre as the dominant organizing principle of teaching the translation of the scientific texts. Genre linguistics is focused on the study and mastering of the overall structure of different genres and the key typological features of the texts that implement them. Its objective is to develop a proper linguistic and contextual competence which includes a compulsory awareness that genres exist to meet the needs of different social groups and reflect their communicative goals and world-view.

A translator who implements a professional translation program is a person who has realized the essence of the translation, the spirit of a foreign language, the features of the chosen genre, the linguistic peculiarities of the genre, and is able to render the entire text in the target language.

\section{REFERENCES}

1. Bhatia, V. K. Analyzing Genre: Language Use in Professional Settings / V. K. Bhatia. - London: Longman, 1993. - 246 p.

2. Flowerdew, J. An Educational, or Process, Approach to the Teaching of Professional Genres / J. Flowerdew // ELT Journal. - 1993. - Vol. 47. - № 4. - P. 305-316.

3. Flowerdew, L. Using a Genre-based Framework to Teach Organizational Structure in Academic Writing / L. Flowerdew // ELT Journal. - 2000. - Vol. 54. - № 4. - P. 369378.

4. Johns, A. M. Text, Role, and Context: Developing Academic Literacies. - Cambridge: Cambridge University Press, 1997. $-171 \mathrm{p}$.

5. Nunan, D. Exploring Genre and Register in Contemporary English / D. Nunan // English Today. - 2008. - Vol. 24. - №

6. Paltridge, B. Genre and the Language Learning Classroom. Ann Arbor: the University of Michigan Press, 2001. - 154 p.

7. Swales, J. M., Feak C. B. Academic Writing for Graduate Students: Essential Tasks and Skills. - Second edition. Ann Arbor: the University of Michigan Press, 2004. - 332 p.

8. Swales, J. M., Feak C. B. Academic Writing for Graduate Students: Course for Non-native Speakers of English. - Ann Arbor: the University of Michigan Press, 1994. - 254 p.

9. Swales, J. M. Genre Analysis: English in Academic and Research Settings / J. M. Swales. - Cambridge: Cambridge University Press, 1990. -260 p.

10. Widdowson, H. G. Explorations in Applied Linguistics. Oxford: Oxford University Press, 1984. - 202 p. 